\title{
Glycosaminoglycans and other sulphated polysaccharides in calculogenesis of urinary stones
}

\author{
E. R. Boevé, L. C. Cao, C. F. Verkoelen, J. C. Romijn, W. C. de Bruijn, and F. H. Schröder \\ Department of Urology, Academic Hospital Dijkzigt and the AEM-Unit, Clinical Pathological Institute, Erasmus University, Rotterdam, \\ The Netherlands
}

\begin{abstract}
Summary. Naturally occurring glycosaminoglycans (GAGs) and other, semisynthetic, sulphated polysaccharides are thought to play an important role in urolithiasis. Processes involved in urinary stone formation are crystallization and crystal retention. Oxalate transport and renal tubular cell injury are determining factors in these processes. In this article experimental results concerning the possible mechanisms of action of GAGs and other sulphated polysaccharides are reviewed. GAGs are inhibitors of crystal growth and agglomeration and possibly also of nucleation. They can prevent crystal adherence, correct an abnormal oxalate flux and prevent renal tubular cell damage.
\end{abstract}

Sulphated polysaccharides can be divided in two subgroups, namely, glycosaminoglycans (GAGs) and other semi-synthetic sulphated polysaccharides. GAGs are polyanionic polysaccharide chains composed of repeating disaccharides of identical composition and variable lengths. Their molecular weight varies between $2 \times 10^{3}$ and $3 \times 10^{6}$ $\mathrm{Da}$. All have a similar structure with one of the five principal polymers hyaluronate, chondroitin, keratan, dermatan or heparan. All except hyaluronic acid may be covalently attached to protein as proteoglycans [35].

GAGs are widely distributed in the body. Many physiological functions are attributed to these substances, but little is known in detail about their synthesis, distribution and metabolism. In adults, approximately $250 \mathrm{mg} \mathrm{GAG}$ is produced each day, only $10 \%$ of which is excreted in the urine. Urinary GAGs are enzymatic degradation products of proteoglycans that are excreted by glomerular filtration [50]. Renal tubular secretion or reabsorption has not been demonstrated [37]. Their excretion shows a circadian rhythm. Men excrete significantly more GAGs per $24 \mathrm{~h}$ than women, the levels varying between 10 and $30 \mu \mathrm{mol} /$ day as based upon measurements of the glucuronic acid moiety. Normal urine contains about $2 \%$ GAGs. Of the

Correspondence to: E. R. Boevé
GAG fraction, about $60 \%$ is chondroitin sulphate, $18 \%$ is keratan sulphate, $15 \%$ is heparan sulphate, $4 \%$ hyaluronic acid and $2 \%$ is dermatan sulphate [29]. Only is heparin does not appear in human urine. Many investigators $[5,14,17,25,33,61,64,65]$ have studied urinary GAGs, but it remains unclear whether there are qualitative and/or quantitative differences in urinary GAGs between urolithiasis patients and normal individuals. Moreover, we lack detailed knowledge about the role of GAGs in cell membrane function and its influence on cell surface properties.

As early as 50 years ago, Butt [11] used an enzymatic induced hypersecretion of GAGs in the prevention of urolithiasis. This and the introduction of heparin-like drugs and sodium pentosan polysulphate (SPP) induced the interest of investigators to use these substances in stone prevention. Norman et al. [51, 52] first reported on the use of SPP in the treatment of urolithiasis. In humans, approximately $3 \%$ of this drug is excreted in the urine after oral administration [58]. Animal studies with tritiated SPP demonstrated a high concentration of the label in rat urine and the urothelium after either i.v. or oral administration [53]. After 30 days of oral administration to rats the total GAG content in kidney tissue had not significantly changed, but a significant increase in the heparin fraction was observed. Changes in other GAG fractions observed during treatment with an induction of a lithogenic diet were prevented with simultaneous SPP administration [71].

In humans after the administration of [ $\left.{ }^{125} \mathrm{I}\right]-\mathrm{SPP}$, degradation products were found in urine; these occurred in a sulphated and desulphated macromolecular form and in a depolymerized form [45]. However, dermatan sulphate is well absorbed after oral administration but appears unchanged in urine [16]. Other semi-synthetic polysaccharides used in stone research are G871, G872 (both derived from seaweed [7, 13]) and CG-120 [48]. The effect of GAGs on calcium oxalate crystallization in urine has recently been reviewed by Hesse et al. [35] and Cao et al. [12]. In this review we pay extra attention to recently introduced, new possible mechanisms for GAGs in stone 
Table 1. The effect of sulphated polysaccharides on crystallization in vitro

\begin{tabular}{|c|c|c|c|c|c|c|c|c|}
\hline Authors & $\begin{array}{l}\text { Refer- } \\
\text { ence }\end{array}$ & Year & Substances & Crystals & & \multicolumn{3}{|c|}{ Effect on crystallization } \\
\hline Robertson et al. & {$[62]$} & 1973 & CS-A Heparin & $\mathrm{CaOx}$ & SCGM & & Inh. & Inh. \\
\hline Hansen et al. & {$[32]$} & 1976 & Heparin HA CS-A, B, C & $\mathrm{CaP}$ & & & Inh. & Inh. \\
\hline Bowyer et al. & [9] & 1979 & CS-A CS-C & $\mathrm{CaOx}$ & SCGM & & Inh. & Inh. \\
\hline Ryall et al. & {$[66]$} & 1981 & CS Heparin & $\mathrm{CaOx}$ & SCGM & & Inh. & Inh. \\
\hline Martin et al. & {$[44]$} & 1984 & SPP & $\mathrm{CaOx}$ & SCGM & & Inh. & \\
\hline Norman et al. & {$[52]$} & 1985 & SPP & $\mathrm{CaOx}$ & MSMPR & & Inh. & Inh. \\
\hline Fellström et al. & [19] & 1985 & Heparin SPP & $\mathrm{CaOx}$ & SCGM & & Inh. & \\
\hline Kok et al. & [39] & 1988 & CS Heparin SPP & $\mathrm{CaOxH}_{2} \mathrm{O}$ & SCGM & & Inh. & No effect \\
\hline Danielson et al. & {$[15]$} & 1989 & SPP & $\mathrm{CaOx}$ & SCGM & & Inh. & \\
\hline McLean et al. & {$[46]$} & 1990 & CS-A, C Heparin & Struvite & ISM & No effect & No effect & \\
\hline Grases et al. & {$[30]$} & 1991 & CS SPP & UA & Turb. & Inh. & Inh. & Inh. \\
\hline Miyazawa et al. & {$[48]$} & 1991 & CG-120 SPP & $\mathrm{CaOx}$ & $\begin{array}{l}\text { MSMPR } \\
\text { SCGM }\end{array}$ & $\begin{array}{l}\text { Inh. } \\
\text { Inh. }\end{array}$ & Inh. & Inh. \\
\hline Cao et al. & [13] & 1992 & SPP G871 G872 & $\mathrm{CaOxH}_{2} \mathrm{O}$ & $\mathrm{CCM}$ & & Inh. & Inh. \\
\hline Boevé et al. & {$[7]$} & 1993 & SPP G871 G872 & $\mathrm{CaP}$ & $\mathrm{CCM}$ & & Inh. & Inh. \\
\hline
\end{tabular}

Nucl., Nucleation; Aggr., aggregation; $C S$, chondroitin sulphate; $H A$, hyaluronic acid; $C a P$, calcium phosphate; $U A$, uric acid; $S C G M$, seeded crystal growth model; $M S M P R$, mixed suspension,

mixed product removal system; ISM, infection stone model; Turb., turbidity measurement; Inh., inhibition; Prom., promotion

sorption of heparin on sodium acid urate crystals [22]. Fellström et al. [20] confirmed these data with binding experiments with radiolabeled heparin, chondroitin sulphate and SPP. Under a condition of an excess of sodium urate crystals, up to $90 \%$ of the offered chondroitin sulphate was bound, whereas only $40 \%$ of the SPP was bound. None of the polysaccharides used showed binding to uric acid crystals under similar conditions. In 1989, Fellström et al. [21] showed a very high affinity for the same polysaccharides to calcium oxalate crystals. Binding was not influenced by the $\mathrm{pH}$ of the solution, but a lower binding affinity at a higher ionic strength was observed. Angell and Resnick [1] applied the Langmuir isotherm absorption method to study the surface interaction between calcium oxalate and GAGs. Components known to be weak inhibitors bind with less affinity than strong inhibitors. Zeta-potential measurements provided evidence for the binding of SPP and two newly developed sulphated polysaccharides, G871 and G872, to calcium oxalate monohydrate [13] and calcium phosphate crystals [7]. The highly negatively charged polysaccharides reduce the zeta potential of the crystals, the effect being more pronounced with G872 than with G871 or SPP.

The effect of sulphated polysaccharides on crystallization has been studied in vitro by many investigators using different crystallization models with different crystals, different media and different inhibiting substances (Table 1). The majority of the investigators have found that crystal growth and aggregation is inhibited to various degrees. The results obtained in different model systems are not with the same method a $\mathrm{Ca}^{2+}-$ and $\mathrm{Mg}^{2+}$-dependent ad- 
comparable and may or may not be considered representative for the processes occurring in the human urinary system. We tested all available GAGs and semi-synthetic polysaccharides in a constant composition system and a seeded crystal system (unpublished data). According to our results, the relative inhibitory activity on calcium oxalate crystal growth is: semi-synthetic sulphated polysaccharides $>$ heparin $>$ chondroitin sulphate. Several factors must be considered that can influence the results obtained, including (a) the total polysaccharide mass bound to the crystal surface, (b) the molecular weight, (c) the site and degree of sulphation of the polysaccharides and (d) the existing state of the polymers in solution.

The effect of the different polysaccharides on crystals other than $\mathrm{CaOx}$ is less well established. Several investigators have shown that only low-molecular-weight substances such as citrate, magnesium, phosphocitrate, pyrophosphate and diphosphonates can inhibit calcium phosphate crystallization. Hansen et al. [32] and Boevé et al. [7] showed inhibition of calcium phosphate crystallization by heparin, hyaluronic acid, SPP and G872. We did not find a report on the inhibition of uric acid growth or aggregation. Recently McLean et al. [46] showed no effect of sulphated polysaccharides on struvite formation.

Colloidal monosodium urate was believed to reduce the inhibitory activity of urinary GAGs in calcium oxalate urolithiasis with hyperuricosuria [63, 67]. Recently, Grover et al. [31] concluded that "urate does not exist in urine in a colloidal or crystalline form, and that the promotion of calcium oxalate crystallization by urate is not a consequence of its reducing the inhibitory activity of GAGs".

Butt [11] introduced the idea that urinary colloids might be active in the prevention of urolithiasis. The highly sulphated and therefore highly negatively charged polysaccharides are supposed to bind to the urinary crystals and in that way stabilize the urinary colloidal system. According to the protective colloidal theory, crystal aggregation will be inhibited with an increase of the crystal surface charge. The inhibitory activity of different sulphated polysaccharides is related to their surface charge, as has been elegantly demonstrated with the zeta-potential measurements of Robertson et al. [62] and Cao et al. [13].

Apart from the GAG-crystal interaction, there is evidence that urinary polysaccharides can inhibit calcium oxalate crystallization by lowering the urinary supersaturation. Hesse et al. [34] found with an equilibrium analysis that $1 \mu \mathrm{mol}$ chondroitin sulphate can bind $0.76 \mu \mathrm{mol}$ calcium. This binding can, dependent on the $\mathrm{pH}$ value, be inhibited by urate ions to a maximum of $31 \%$. We do not think that this effect will have a significant impact on the urinary supersaturation, since the concentration of urinary GAGs can exert only little effect, if any, on the urinary calcium concentration.

In an animal experiment using a lithogenic diet with sodium glycolate in the rat, Subha and Varalakshmi [70] have found that after oral administration of SPP, the urinary oxalate and calcium excretion decreases by $25 \%$ and $20 \%$, respectively. The glycolate-induced hyperoxaluria is reduced by $20 \%$ after oral administration of SPP. They also found a moderate increase in urinary magnesium levels after 30 days of SPP administration. However, Michelacci et al. [47] did not find a protective effect on experimentally induced calcium oxalate crystallization in the rat bladder following intraperitoneal administration of chondroitin sulphate to rats.

GAGs can be found in matrix from stone. Heparan sulphate is the main GAG occurring in soluble stone matrix [73]. It can be speculated as to whether GAGs in the stone matrix are promoters of crystallization of whether they are inhibitors adsorbed to the crystal surface.

\section{Prevention of crystal adherence}

Crystallization alone is insufficient to explain the occurrence of urinary stones. Adherence of crystals to the urothelium is an additional prerequisite for stone formation, as Finlayson et al. [23] have suggested. These authors calculated that the transition time of urine is too short for free crystals to grow into urinary stones. Therefore, it is important to study the interaction of crystals with mucosal surfaces. In fact, not only urolithiasis but also urinary tract infection and bladder cancer may be mediated by the adherence to the urothelium of, respectively, crystals, bacteria or carcinogens.

The normal urothelium is lined with a GAG layer [49]. Parsons and co-workers $[56,57]$ showed in a good experimental set-up that the GAG layer, produced by transitional cells lining the rabbit bladder, prevented bacterial adherence. When this GAG layer was removed by protamine sulphate treatment, bacterial adherence increased. Exogenous sulphated polysaccharides can reverse the protamine-induced changes. Gill et al. [27] demonstrated the same effect on calcium oxalate crystal adherence. They showed an elevation of the metastable limit for nucleation and an absence of nucleation on the reaction container surface in a urothelium-lined system. When the urothelium was injured with a detergent there was a marked increase in crystal adhesion [26]. Heparin had a pronounced effect in restoring the normal crystal adhesion properties of the injured urothelium. Chondroitin sulphate-C and hyaluronic acid had no protective effect [28]. Smith [69] demonstrated that chondroitin sulphate and heparin fully restored the anti-adherence properties of the urothelium after acid treatment, whereas SPP caused only a partial restoration.

The above-mentioned experimental models in vivo show the importance of an intact epithelial membrane. Sulphated polysaccharides are a very important constituent of this membrane. They create a highly organized, impermeable water layer that might be responsible for the prevention of crystal adherence.

Recently, more investigators have realized the importance of the role that renal tubular cells play in initial stone formation. The concept that cellular injury and dysfunction are underlying causes of urolithiasis has been accepted. Mandell et al. [43] studied the crystal-membrane interactions with red blood cells in vitro. The membranolysis induced by weddellite and sodium urate was inhibited after the addition of chondroitin sulphate-A, chondroitin 
sulphate-C and heparin. Later, Riese et al. [60] developed a cell culture model of renal papillary collecting tubule cells in which they demonstrated cell injury (loss of cell membrane polarity induced by ethylene glycol tetraacetic acid, EGTA) enhanced calcium oxalate crystal adherence. GAGs have not yet been tested in this model.

More recently, crystal adherence studies have been carried out in our laboratory using renal tubular cell lines. Verkoelen et al. [72] demonstrated a time- and concentration-dependent adhesion and/or endocytosis of ${ }^{14} \mathrm{C}$ baleled calcium oxalate monohydrate crystals to monolayers of MDCK and LLC-PK1 cells. It was demonstrated that monolayers with a higher degree of differentiation were better protected against crystal adherence. Pretreatment of the crystals with sulphated polysaccharides prevented crystal adherence, in contrast to pretreatment of the monolayer with these compounds. In general, semisynthetic polysaccharides are more effective in preventing crystal-cell interactions than are GAGs [72]. These cell models will be used to study the interaction between crystals and renal tubular cells in more detail. Primary cultures of proximal and distal renal tubular cells are needed for more conclusive results.

Parsons et al. [59] have found an inhibition of sodium urate crystal adherence to the bladder surface by SPP. They have also demonstrated that in the experimental setting, pretreatment of the crystals is more effective than pretreatment of the mucus-deficient bladders. Their results have been confirmed by Pantazopoulos et al. [55]. One can speculate that the previously well-documented interaction between polysaccharides and urinary crystals is of more importance in stone prevention than an intact GAG coating of the urothelium. The GAG coating produced by the cells is a very highly organized layer. The GAGs added to the culture medium or the bladder cannot easily be incorporated in this layer.

Recently, Lieske and Toback [42] found evidence that calcium oxalate monohydrate, brushite and hydroxyapatite crystals are endocytosed by MDCK and BSC-1 cell lines. Heparin is one of the substances inhibiting this process. These investigators think that the surface of the cell, rather than the crystal, appears to be the locus at which heparin and other substances act to inhibit endocytosis. Crystal endocytosis could be an important pathogenic step in urolithiasis.

Future studies will have to reveal whether increased crystal adherence to cells is caused by a defective GAG layer on the cell surface or whether the crystals themselves induce cell dysfunction (by endocytosis?), resulting in an abnormal surface coating. Is there secretion of GAGs by renal tubular cells and, if so, is this of importance in stone prevention?

\section{Correction of abnormal oxalate transport}

Hyperoxaluria is now considered to be the most important risk factor in calcium oxalate urolithiasis. Renal leak, intestinal hyperabsorption or high degrees of endogenous oxalate production can cause high levels of oxalate excretion. It is unknown as to whether or not there is a common (inherited) factor involved in idiopathic calcium oxalate urolithiasis.

Baggio et al. [3] reported an increased oxalate flux across red-cell (RBC) membranes in calcium nephrolithiasis patients. They speculated that in idiopathic urolithiasis patients there may be a genetic cellular defect or membrane disorder causing the increase in oxalate transport. This could also involve the renal oxalate handling. The defect can be corrected by administration of a mixture of heparan and dermatan sulphate [4]. These investigators demonstrated an increased phosphorylation of anion transporters (band 3 protein) in RBC ghosts derived from urolithiasis patients that may result in a high level of oxalate transport. This phosphorylation can be reduced by treatment with GAGs.

\section{Protective effect of GAGs on renal tissue}

There is increasing evidence that some form of renal tubular disfunction such as abnormal renal handling of various ions [68] might be related to tubular damage (as evidenced by enzymuria) $[2,36]$ and be involved in urolithiasis. Recently, Subha and Varalakshmi [70] found a significantly increased urinary excretion of enzymes (lactate dehydrogenase, LDH; alkaline phosphatase; $\gamma$-glutamyl transpeptidase, $\gamma$-GT, and $\beta$-glucuronidase) in rats treated with a stone-inducing diet containing sodium glycolate. This finding indicates proximal tubular damage and membranuria. SPP treatment normalized the excretion of LDH and moderately decreased that of alkaline phosphatase, $\gamma$-GT and $\beta$-glucuronidase.

In animal models, crystal formation can be induced by renal tubular injury with gentamycin sulphate or ammonium chloride with ethylene glycol $[8,40]$. A variety of ultrastructural changes appear in the proximal tubular cells. Also, a dilatation of the proximal renal tubules occurs and, later, intracellular crystals appear; these have been proven to be calcium oxalate monohydrate crystals [10]. In this animal model, orally applied exogenous sulphated polysaccharides G872 and SPP can prevent the described tubular cell injury [6].

The long-term administration of heparin and dermatan sulphate can also prevent morphological renal alteration and albuminuria in diabetic rats [24]. Abnormal GAG metabolism could determine the loss of glomerular basement membrane anionic charges. Gambaro et al. [24] demonstrated in rats with streptozotocin-induced diabetes that daily s. c. injections of heparin and dermatan sulphate increased the glomerular anionic charge and prevented glomerular basement membrane thickening. The glomerular filtration rate did not decrease and albuminuria did not occur.

\section{Open questions}

In the past 20 years, much effort has been invested in discovering the cause of urolithiasis. Several test systems in vitro and in vivo have been developed. It is now clear that supersaturation is not the only factor that should be taken into account. The lack of inhibitory activity might be the 
most important risk factor in urolithiasis. GAGs are probably among the strongest inhibitors of crystallization. We think that it is of great importance that the factors influencing the role of GAGs in urolithiasis be clarified in detail:

1. Is there a difference in urinary GAGs between stoneformers and healthy persons in synthesis, metabolism, molecular structure or conformation in urine?

2. Which individual GAG is an inhibitor and which is a promoter of crystallization?

3 . What is the mechanism of crystal adherence and crystal endocytosis? How are these processes influenced by sulphated polysaccharides?

4. Can semi-synthetic polysaccharides prevent renal tubular cell damage in stone patients?

5. Is it possible to prevent stone recurrence by treatment with semi-synthetic sulphated polysaccharides?

6. Can the function of semi-synthetic polysaccharides be improved by increasing the degree of sulphation or changing the molecular structure?

To address these and numerous other questions remaining open, ongoing research will have to focus on both the urinary and the cellular processes involved in stone formation. Such research will answer some questions but will probably put forward new ones as well.

\section{References}

1. Angell AH, Resnick MI (1989) Surface interaction between glycosaminoglycans and calcium oxalate. J Urol 141:12551258

2. Baggio B, Gambaro G, Ossi E, Favaro S, Borsati A (1983) Increased urinary excretion of renal enzymes in idiopathic calcium oxalate nephrolithiasis. J Urol 129:1161-1162

3. Baggio B, Gambaro G, Marchini F, Cicerello E, Tenconi R, Clementi M, Borsati A (1986) An inheritable anomaly of redcell oxalate transport in "primary" calcium nephrolithiasis correctable with diuretics. N Engl J Med 314:599 604

4. Baggio B, Gambaro G, Marchini F, Marzaro G, Williams HE, Borsati A (1991) Correction of erythrocyte abnormalities in idiopathic calcium-oxalate nephrolithiasis and reduction of urinary oxalate by oral glycosaminoglycans. Lancet 338:403-405

5. Bek-Jensen H, Tiselius HG (1991) Inhibition of calcium oxalate crystallization by urinary macromolecules. Urol Res 19: $165-169$

6. Boevé ER, Cao LC, Schröder FH, Ketelaars GAM, Vermey M, Bruijn WC de (1990) The influence of 3 exogenous glycosaminoglycans on the experimental induction of microliths in rats. Urol Res 18:62

7. Boevé ER, Cao LC, Bruijn WC de, Robertson WG, Schröder FH (1993) The effect of two semi-synthetic glycosaminoglycans (G871, G872) on the zeta potential of calcium phosphate crystals and on growth and agglomeration. J Urol 149: $441 \mathrm{~A}$

8. Boevé ER, Ketelaars GAM, Vermeij M, Cao LC, Schröder FH, Bruijn WC de (1993) An ultrastructural study of experimentally induced microliths in rat proximal and distal tubules. J Urol 149:893-899

9. Bowyer RC, Brockis JG, McCulloch RK (1979) Glycosaminoglycans as inhibitors of calcium oxalate crystal growth and aggregation. Clin Chim Acta 95:23-28

10. Bruijn WC de, Ketelaars GAM, Boevé ER, Sorber CWJ, Cao LC, Schröder FH (1993) Electron energy-loss spectroscopical and image analysis of experimentally induced rat mocroliths. J Urol 149:900-905

11. Butt AJ (1952) Role of protective urinary colloids in prevention of lithiasis. J Urol 67:450-459

12. Cao LC, Boevé ER, Schröder FH (1991) The mechanisms of action of glycosaminoglycans (GAGs) in calcium oxalate stone prevention: a review. J Lithotripsy Stone Dis 3:324-333

13. Cao LC, Boevé ER, Schröder FH, Robertson WG, Ketelaars GAM, Bruijn WC de (1992) The effect of two new semi-synthetic glycosaminoglycans (G871, G872) on the zeta potential of calcium oxalate crystals and on growth and agglomeration. J Urol 147: 1643-1646

14. Caudarella R, Stefani F, Rizzoli E, Malavolta N, D'Antuono G (1983) Preliminary results of glycosaminoglycan excretion in normal and stone forming subjects: relationship with uric acid excretion. J Urol 129:665-667

15. Danielson BG, Fellström B, Wikström B (1989) Glycosaminoglycans as inhibitors of renal stone formation. In: Walker VR, Sutton RAL, Cameron ECB, Pak CYC, Robertson WG (eds). Urolithiasis. Plenum, New York, pp 101-104

16. Dawes J, Hodson BA, Pepper DS (1989) The absorption, clearance and metabolic fate of dermatan sulphate administerd to man - studies using a radioiodinated derivative. Thromb Haemos 62:945-949

17. DiFerrante N, Rich C (1956) The determination of acid aminopolysaccharide in urine. J Lab Clin Med 48:491-494

18. Drach GW, Sarig S, Randolph AD, Thorson S (1982) The paradox of inhibition and enhancement of the formation of urinary stones. Urol Res 10:165-168

19. Fellström B, Danielson BG, Ljunghall S, Wikström B (1985) The inhibition of calcium oxalate crystal growth by chondroitin sulphates, heparin, pentosan polysulphate and TammHorsfall glycoprotein. In: Schwille PO, Smith LH, Robertson WG, Vahlensieck W (eds) Urolithiasis and related clinical research. Plenum, New York, pp 887-890

20. Fellström B, Lindsjö M, Danielson BG, Ljunghall S, Wikström B (1986) Binding of glycosaminoglycans to sodium urate and uric acid crystals. Clin Sci 71:61-64

21. Fellström B, Lindsjö M, Danielson BG, Karlsson FA, Ljunghall S (1989) Binding of glycosaminoglycan inhibitors to calcium oxalate crystals in relation to ionic strength. Clin Chim Acta 180:213-220

22. Finlayson B, Du Bois L (1978) Adsorption of heparin on sodium acid urate. Clin Chim Acta 84:203-206

23. Finlayson B, Khan SR, Hackett RL (1984) Mechanisms of stone formation - an overview. Scan Microsc Int 3:1419-1425

24. Gambaro G, Cavazzana AO, Luzi P, Piccoli A, Borsati A, Crepaldi G, Marchi E, Venturini AP, Baggio B (1992) Glycosaminoglycans prevent morphological renal alterations and albuminuria in diabetic rats. Kidney Int 42:285-291

25. Gianotti M, Genestar C, Palou A, Pons A, Conte A, Grases F (1989) Investigation of GAGs on 24-hour and 2-hour urines from calcium oxalate stone formers and healthy subjects. Int Urol Nephrol $21: 281-288$

26. Gill WB, Ruggiero KJ, Straus FH (1980) Crystallization studies in an urothelial-lined living test tube (the catheterized female rat bladder). I. Calcium oxalate crystal adhesion to the chemically injured rat bladder. Invest Urol 17:259-261

27. Gill WB, Ruggiero KJ, Fromez MC (1980) Elevation of the metastable limits and absence of container surface nucleation for calcium oxalate crystallization in a urothelial-lined system as compared to glass containers. Invest Urol 18:158-160

28. Gill WB, Jones KW, Ruggiero KJ (1982) Protective effects of heparin and other sulfated glycosaminoglycans on crystal adhesion to injured urothelium. J Urol 127:152-154

29. Goldberg JM, Cotlier E (1972) Specific isolation and analysis of mucopolysaccharides (glycosaminoglycans) from human urine. Clin Chim Acta $41: 19-27$

30. Grases F, Costa-Bauzá A, March JG (1991) Glycosaminoglycans, uric acid and calcium oxalate urolithiasis. Urol Res 19: $375-380$ 
31. Grover PK, Ryall RL, Marshall VR (1992) Calcium oxalate crystallization in urine: role of urate and glycosaminoglycans. Kidney Int $41: 149-154$

32. Hansen NM, Felix R, Bisaz S, Fleisch H (1976) Aggregation of hydroxyapatite crystals. Biochim Biophys Acta 451:549-559

33. Hesse A, Wuzel H, Vahlensieck W (1986) The excretion of glycosaminoglycans in the urine of calcium-oxalate-stone patients and healthy persons. Urol Int $41: 81-87$

34. Hesse A, Wuzel H, Krampitz G, Vahlensieck W (1987) Experimental determination of the kinetics of calcium-binding with chondroitin sulphate and the effects of uric acid on this process. Urol Res 15:93-97

35. Hesse A, Wuzel H, Vahlensieck W (1991) Significance of glycosaminoglycans for the formation of calcium oxalate stones. Am J Kidney Dis 17:414-419

36. Khan SR, Shevock PN, Hackett RL (1992) Acute hyperoxaluria, renal injury and calcium oxalate urolithiasis. J Urol 147: 226-230

37. Kerby GP (1954) The excretion of glucuronic acid and of acid mucopolysaccharides in normal human urine. J. Clin Invest 33 : $1168-1174$

38. Kohri K, Garside J, Blacklock NJ (1989) The effect of glycosaminoglycans on the crystallisation of calcium oxalate. Br J Urol 63:584-590

39. Kok DJ, Papapoulos SE, Blomen LJMJ, Bijvoet OLM (1988) Modulation of calcium oxalate monohydrate crystallization kinetics in vitro. Kidney Int $34: 346-350$

40. Kumar S, Sigmon D, Miller T, Carpenter B, Khan S, Malhotra R., Scheid C, Menon M (1991) A new model of nephrolithiasis involving tubular dysfunction/injury. J Urol 146:1384-1389

41. Leal JJ, Finlayson B (1977) Adsorption of naturally occurring polymers onto calcium oxalate crystal surfaces. Invest Urol 14 : $278-283$

42. Lieske JC, Toback FG (1993) Regulation of renal epithelial cell endocytosis of calcium oxalate monohydrate crystals. Am J Physiol [F] 264:800-807

43. Mandel NS, Mandel GS, Hasegawa AT (1987) The effect of some urinary stone inhibitors on membrane interaction potentials of stone crystals. J Urol 138:557-562

44. Martin X, Werness PG, Bergert JH, Smith LH (1984) Pentosan polysulfate as an inhibitor of calcium oxalate crystal growth. J Urol 132:786-788

45. MacGregor IR, Dawes J, Paton L, Pepper DS, Prowse CV, Smith M (1984) Metabolism of sodium pentosan polysulphate in man catabolism of iodinated derivatives. Thromb Haemost 51:321-325

46. McLean RJC, Downey J, Claphan L, Nickel JC (1990) Influence of chondroitin sulphate, heparin sulphate, and citrate on Proteus mirabilis-induced struvite crystallization in vitro. J Urol 144:1267-1271

47. Michelacci YM, Boim MA, Bergamaschi CT, Rovigatti RM, Schor N (1992) Possible role for chondroitin sulfate in urolithiasis: in vivo studies in an experimental model. Clin Chim Acta $208: 1-8$

48. Miyazawa K, Suzuki K, Tsugawa R (1991) A study of crystallization on urolithiasis in vitro (in Japanese). Hinyokika-kiyo 37: 1091-1096

49. Monis B, Dorfman HD (1967) Some histochemical observations on transitional epithelium of man. J Histochem Cytochem $15: 475-481$

50. Newton DJ, Scott JE, Ahmad S (1979) Circadian rhythms and the urinary excretion of acid glycosaminoglycans in normal human adults. Connect Tissue Res 7:47-55

51. Norman RW, Scurr DS, Robertson WG, Peacock M (1984) Inhibition of calcium oxalate crystallization by pentosan polysulphate in control subjects and stone formers. Br J Urol 56:594-598

52. Norman RW, Scurr DS, Robertson WG, Peacock M (1985) Sodium pentosan polysulphate as a polyanionic inhibitor of calcium oxalate crystallization in vitro and in vivo. Clin Sci 68:369-371

53. Odlind L, Dencker L, Tengblad A (1987) Preferential localization of ${ }^{3} \mathrm{H}$-pentosanpolysulphate to the urinary tract in rats. Pharmacol Toxicol $61: 162-166$
54. Osswald H, Weinheimer G, Schütt ID, Ernst W (1989) Effective prevention of calcium-oxalate crystal formation in vitro and in vivo by pentosan polysulfate. In: Walker VR, Sutton RAL, Cameron ECB, Pak CYC, Robertson WG (eds) Urolithiasis. Plenum, New York, pp 141-144

55. Pantazopoulos D, Legakis N, Antonakopoulos G, Sofras F, Dimopoulos C (1987) The effect of pentosanpolysulphate and carbenoxolone on bacterial adherence to the injured urothelium. Br J Urol 59:423-426

56. Parsons CL (1982) Prevention of urinary tract infection by the exogenous glycosaminoglycan sodium pentosan polysulfate. J Urol 172: 167-169

57. Parsons CL, Greenspan C, Moore SW, Mulholland SG (1977) Role of surface mucin in primary antibacterial defence of bladder. Urology 9:48-52

58. Parsons CL, Schmidt JD, Pollen JJ (1983) Successful treatment of interstitial cystitis with sodium pentosanpolysulphate. J Urol 130:51-53

59. Parsons CL, Danielson B, Fellström B (1985) Inhibition of sodium urate crystal adherence to bladder surface by polysaccharide. J Urol 134:614--616

60. Riese RJ, Mandel NS, Wiessner JH, Mandel GS, Becker CG, Kleinman JG (1992) Cell polarity and calcium oxalate crystal adherence to cultured collecting duct cells. Am J Physiol [F] $262: 177-184$

61. Robertson WG, Scurr DS (1986) Modifiers of calcium oxalate crystallization found in urine. I. Studies with a continuous crystallizer using an artificial urine. J Urol 135:1322-1326

62. Robertson WG, Peacock M, Nordin BEC (1973) Inhibitors of the growth and aggregation of calcium oxalate crystals in vitro. Clin Chim Acta 43:31-37

63. Robertson WG, Knowles F, Peacock M (1976) Urinary mucopolysaccharide inhibitors of calcium oxalate crystallization. In: Fleisch $\mathrm{H}$, Robertson WG, Smith LH, Vahlensieck W (eds) Urolithiasis research. Plenum, New York London, pp 331-334

64. Robertson WG, Peacock M, Heyburn PJ, Marshall DH, Clark PB (1978) Risk factors in calcium stone disease of the urinary tract. Br J Urol 50:449-454

65. Ryall RL, Marshall VR (1983) The value of the 24-hour urine analysis in the assessment of stone-formers attending a general hospital outpatient clinic. Br J Urol 55: 1-5

66. Ryall RL, Harnett RM, Marshall VR (1981) The effect of urine, pyrophosphate, citrate, magnesium and glycosaminoglycans on the growth and aggregation of calcium oxalate crystals in vitro. Clin Chim Acta 112:349-356

67. Ryall RL, Harnett RM, Marshall VR (1986) The effect of monosodium urate on the capacity of urine, chondroitin sulphate and heparin to inhibit calcium oxalate crystal growth and aggregation. J Urol 135:174-177

68. Sakhaee K, Nicar MJ, Brater DC, Pak CYC (1985) Exaggerated natri-uretic and calciuric responses to hydrochlorothiazide in renal hypercalciuria but not in absorptive hypercalciuria. $\mathrm{J}$ Clin Endocrinol Metab 61:825-829

69. Smith $\mathrm{C}(1985){ }^{\mathrm{I}}{ }^{\mathrm{C}} \mathrm{C}$-Calcium oxalate $(\mathrm{CaOx})$ adherence in the rat bladder. In: Schwille PO, Smith LH, Robertson WG Vahlensieck W (eds) Urolithiasis and related clinical research Plenum, New York, pp 949-952

70. Subha K, Varalakshmi P (1993) Alteration in some risk ractors and urinary enzymes in urolithiatic rats treated with sodium pentosan polysulphate. Biochem Mol Biol Int 29:271-280

71. Subha K, Varalakshmi P (1993) Changes in renal tissue glycosaminoglycans in urolithiatic rats treated with sodium pentosan polysulphate. Med Sci Res 21:233-234

72. Verkoelen CF, Romijn JC, Bruijn WC de, Boevé ER, Cao LC, Schröder FH (1993) Oxalate handling and interaction with calcium oxalate crystals by renal epithelial cells cultured on porous supports. J Urol 149:439A

73. Yamaguchi S, Yoshioka T, Utsunomiya M, Koide T, Osafune M, Okuyama A, Sonoda T (1993) Heparan sulfate in the stone matrix and its inhibitory effect on calcium oxalate crystallization. Urol Res $21: 187-192$ 